\section{OS JOGOS DAS CRIANÇAS NOS RECREIOS DAS ESCOLAS DO 1 CICLO DO ENSINO BÁSICO DO NORTE DE PORTUGAL}

\author{
CHILDREN'S GAMES DURING SCHOOL RECESS IN THE FIRST CYCLE OF \\ BASIC EDUCATION IN NORTHERN PORTUGAL
}

\begin{abstract}
LOS JUEGOS DE LOS NIÑOS EN LOS RECREOS DE LAS ESCUELAS DEL PRIMER CICLO DE LA ENSEÑANZA BÁSICA DEL NORTE DE PORTUGAL
\end{abstract}

\author{
Vânia Sofía Pereira*, José Eugenio Rodríguez Fernández**, Beatriz Pereira*, \\ Isabel Condessa***
}

\begin{abstract}
Palavras chave: Jogos e brinquedos. Recreação.

Criança.

Ensino fundamental.

Resumo: Este estudo teve como objetivo identificar os jogos realizados e preferidos nos recreios das escolas do $1^{0}$ ciclo, fazendo a diferenciação entre género e ano de escolaridade. Foi aplicado um questionário em duas escolas do $1^{\circ}$ ciclo do ensino básico do norte de Portugal. A amostra foi constituída por 317 alunos dos 4 anos de escolaridade, dos quais 167 são rapazes e 150 raparigas. Verificamos que os jogos de "correr" e "caçadinhas" são os que se realizam com mais frequência, mas os rapazes também gostam muito de "futebol" e as raparigas de "conversar". 0 estudo confirma a pouca diversificação nos jogos realizados pelos alunos e, de acordo com os resultados, é necessário o enriquecimento das atividades lúdicas desenvolvidas pelas crianças utilizando novas intervenções lúdico-pedagógicas ou novos materiais no espaço de recreio.
\end{abstract}

Keywords:

Play and games.

Recreation.

Children.

Education, primary.

Juegos y juguetes.

Recreación.

Niño.

Educación primaria.
Abstract: This study sought to identify the games played and preferred by children during school recess in the so-called first cycle, breaking that information down by gender and school year. A questionnaire was applied in two basic education schools in northern Portugal. The sample included 317 students from the four years in that stage -167 boys and 150 girls. It found that "running" and "chasing" are the most frequent, even though boys prefer football while girls prefer talking. The study confirms low diversification in the games played by children and, according to its findings, children's playful activities must be enriched by using new playful-pedagogic interventions or new materials during recess.

Resumen: Este estudio tuvo como objetivo identificar los juegos realizados y preferidos por los niños en los recreos de las escuelas de primer ciclo, estableciendo una diferenciación entre el género y el año de escolaridad. Se aplicó un cuestionario en dos escuelas de enseñanza básica en Braga, norte de Portugal. La muestra estuvo formada por 317 alumnos de los cuatro años de escolaridad que dura la etapa, de los cuales 167 son niños y 150 son niñas. Se pudo comprobar que los juegos de "correr" y de "pillar" son los que se realizan con más frecuencia, aunque a los niños les gusta también mucho el fútbol y, a las niñas, conversar unas con otras. El estudio confirma la poca diversificación de los juegos realizados por el alumnado, haciéndose necesario un enriquecimiento de las actividades lúdicas desarrolladas por los niños, utilizando nuevas intervenciones lúdicopedagógicas o nuevos materiales para emplear en el espacio de recreo.
*Universidade do Minho. Braga. Portugal.

E-mail: vania2spereira@ hotmail.com; beatriz@ie.uminho.pt

**Universidade de Santiago de Compostela. Santiago de Compostela. España.

E-mail: geno.rodriguez@usc.es

***Universidade dos Açores. Açores, Portugal.

E-mail: maria.id.condessa@uac.pt

Recebido em: 07-09-2017 Aprovado em: 02-07-2018

DOI: https://doi.org/10.22456/1982-8918.76335 (c) (1) (2) Licence 


\section{INTRODUÇÃO}

Nos recreios as crianças realizam os seus jogos de forma livre e as atividades que realizam potenciam a atividade física e a aquisição de estilos de vida saudáveis, tal como as aulas de Educação Física. Estes momentos são uma boa oportunidade de aprendizagem e desenvolvimento das habilidades motoras e outros jogos livres que providencian benefícios ao nível emocional, criativo e social. É nesse espaço, não estruturado e com pouca intervenção dos adultos, que as crianças expandem a sua criatividade, conhecem os seus limites e aprendem a resolver os seus problemas em interação com os outros e com o ambiente que as rodeia. $A$ atividade lúdica e o jogo podem dar nesta fase um grande contributo nesse sentido (NETO, 2001).

São vários os autores que defendem que os espaços adequados e bem organizados na escola podem contribuir para o pleno desenvolvimento da criança, nomeadamente ao nível do seu desenvolvimento físico-motor. Isto é, as condições do espaço físico envolvente e a forma como este está organizado podem potenciar as aprendizagens motoras da criança através dos jogos que estes espaços estimulam e permitem realizar (GALLAHUE, 2005; KRITCHEVSKY; PRESCOTT, 1977; METZLER, 2005).

Os espaços de recreio devem permitir à criança o desenvolvimento adequado dos seus jogos, possibilitar-lhes uma escolha variada, devem ser convidativos à sua participação e ainda devem facilitar o seu desenvolvimento físico, social, emocional e cognitivo (WALSH, 2008; MURRAY et al., 2013). Walsh (2008) defende ainda que todos os espaços ao ar livre podem ser verdadeiros espaços de aprendizagem tão importantes como as salas de aula, principalmente quando esses espaços exteriores permitem o contacto com a natureza, que pode desempenhar um importante papel em qualquer espaço de recreio, independentemente, do seu tamanho ou configuração.

Desde bem cedo, os pais e professores reforçam certos tipos de atividades lúdicas tidas como desejáveis, criando condições para que elas se reproduzam (oferta de determinados brinquedos, a forma como interagem com as crianças, etc.), e julgam outras como inusitadas, tecendo, muitas vezes, comentários desencorajadores. Assim se vão formando os designados estereótipos de papéis de género, isto é, o que raparigas e rapazes devem "fazer" (AMÂNCIO, 1994). Desta forma, as práticas sociais de raparigas e rapazes são diferentes, ou seja, cada um dos sexos tenderá a ter comportamentos e atitudes, consoante as expectativas sociais (PITCHER; SCHULTZ, 1983).

As qualidades femininas e masculinas, os papéis atribuídos a cada género e os comportamentos tradicionalmente associados mais às mulheres ou aos homens são conceitos extremamente ligados às culturas e tradições de cada povo, ou seja o género é uma construção social (ROHRMANN; EMILSEN, 2015).

A cultura escolar molda e reproduz valores, mesmo quando rapazes ou raparigas se mostram disponíveis para participar em jogos designados como sendo típicos do sexo oposto, são os próprios intervenientes a reproduzir os valores existentes na sociedade e na cultura em que estão inseridos. Em vez de assistirmos a uma construção de valores no recreio escolar, este tem servido para a manutenção dos estereótipos de género. Salientando que a cultura escolar favorece a separação entre géneros (MOURA et al., 2012). 
O recreio escolar condiciona as opções das raparigas e valoriza mais as atividades preferidas pelos rapazes, sendo esta uma possível causa para uma maior prática de atividades físicas dos rapazes do que das raparigas nesse local. Os espaços de recreio estão organizados e foram pensados mais na perspetiva das atividades realizadas pelos rapazes do que nas das raparigas, condicionando a ação e as interações destas no recreio (RIDGERS et al., 2011). Pawlowski et al. (2014) defendem mesmo a criação de zonas exteriores de recreio adaptadas para rapazes e para raparigas.

A influência biológica é apontada, ainda, como explicação para as diferenças entre rapazes e raparigas, ao nível das atividades realizadas. Daí os rapazes participarem mais em atividades físicas vigorosas, tendo, assim, um comportamento mais ativo que as raparigas (SUTTON-SMITH, 1981). Não podemos ignorar, contudo, que se por um lado temos a dimensão biológica, por outro lado temos as construções sociais e históricas que foram produzidas sobre as características biológicas (MOURA et al., 2012).

Em relação às diferenças entre género no que se refere aos jogos praticados nos recreios, o estudo de Harten, Olds e Dollman (2008) aponta para a existência de relação entre o jogo livre, as habilidades motoras e o espaço de jogo disponível nos rapazes, sugerindo que estes são mais ativos em espaços destinados a jogos desportivos ou em espaços amplos, referindo ainda que os rapazes jogam em espaços maiores, enquanto as raparigas jogam em espaços menores.

Os mesmos autores caracterizam o jogo dos rapazes como sendo mais competitivo e agressivo, e o das raparigas como mais cooperativo, e ainda assinalam que os rapazes excluem frequentemente dos seus jogos os elementos que apresentam fraco desempenho motor, enquanto as raparigas tentam atribuir papéis a todos os que querem participar nos seus jogos. É complementado por Lever (1978) que as raparigas conversam com os amigos mais frequentemente do que os rapazes e que se envolvem em jogos competitivos com pouca frequência. Os jogos dos rapazes tendem a ser mais desportivos e os das raparigas têm tendência para ser mais de lazer e mais sedentários (PFISTER, 1993).

No sentido de realçar os extremos da estereotipia entre género, Pomar e Neto (2000) afirmam que os jogos desportivos coletivos, trepar árvores e polícias e ladrões são predominantemente masculinos, enquanto a macaca, o elástico, os batimentos ritmados de mãos e o saltar à corda são predominantemente femininos.

Os objetivos do presente estudo são:

- Identificar os jogos realizados nos recreios das escolas do 1ํciclo;

- Verificar quais são os jogos preferidos pelas crianças no recreio;

- Averiguar as diferenças entre género e ano de escolaridade relativamente aos jogos realizados e preferidos no recreio.

\section{METODOLOGIA}

\subsection{Concepção}

Foi realizado um estudo quantitativo e descritivo-transversal (BISQUERRA, 2004; DEMO, 2005; TUCKMAN, 2012), metodologia utilizada para observar o que acontece com 
o fenómeno de estudo em condições naturais, na realidade e, no nosso caso, porque é um tipo de pesquisa que nos permite identificar o mundo das crianças relativamente ao jogo livre, atividades não dirigidas que realizam no recreio da escola.

\subsection{Amostra}

Participaram no estudo 317 alunos do $1^{\circ}$ ao $4^{\circ}$ ano de escolaridade de duas escolas do $1^{\circ}$ ciclo do ensino básico do norte de Portugal, dos quais 167 rapazes e 150 raparigas, com idades entre os 6 e os 10 anos, sendo a média de idades de 7,45 \pm 1.14 .

\subsection{Instrumento}

Foi aplicado o questionário (BAPTISTA, 2016; CEA, 2014; MAGALHÃES; HILL, 2016) como ferramenta principal para a coleta de dados, um documento que recolhe de forma organizada os indicadores das variáveis envolvidas no objetivo da pesquisa (CASAS; REPULLO; DONADO, 2003).

Após a identificação de dados básicos dos participantes (idade, sexo, ano de escolaridade etc.) o questionário foi distribuído em dois grandes blocos de informação:

a) Recreio Escolar. É composto por quatro questões sobre as perspectivas das crianças em relação ao recreio da escola, a sua caracterização em termos de espaços e materiais existentes e ainda o gosto pelo recreio e a duração do tempo de recreio. Este grupo de questões foi essencial para o estudo, uma vez que permitiu saber que tipo de espaços e materiais as crianças mais utilizam nos recreios, pois estes podem estar associadas ao tipo de actividades que estas realizam durante esse período de tempo.

b) Práticas realizadas e preferidas. Sobre as atividades realizadas no recreio, em que são dadas várias opções. Estas atividades foram selecionadas a partir de um estudo sobre práticas preferidas e realizadas (PEREIRA; NETO, 1997) e também a partir da análise de registos diários de atividades aplicados durante uma semana a duas turmas (incluindo os quatro níveis de escolaridade do $1^{0}$ ciclo) de duas escolas de ensino básico do norte de Portugal.

A partir do cruzamento dos resultados obtidos com a revisão de literatura, as atividades foram sendo incluídas em categorias já existentes (PEREIRA; NETO, 1997) para posteriormente tornarem mais simples a análise dos dados que foram obtidos quando da aplicação do questionário. Ainda são feitas neste grupo duas questões sobre as atividades preferidas.

\subsection{Procedimento}

Foi aplicado o questionário sobre práticas e interações nos recreios do 1ำ ciclo do ensino básico, mas antes foi solicitada autorização para a realização do estudo (Monitorização de Inquéritos em Meio Escolar); também para os diretores das escolas nas que se realizou 0 trabalho e para os pais dos alunos que participaram no estudo. Foram establecidos os seguintes esclarecimentos sobre a aplicação do questionário: 
- Explicação para os alunos das finalidades da pesquisa.

- Alunos de $1^{\circ}$ e $2^{\circ}$ anos. $O$ questionário foi projetado e cada questão foi lida às crianças deste ano de escolaridade. Aguardou-se que todas respondessem a cada questão para passar à seguinte e, em caso de dúvida, um dos investigadores e a professora titular de turma ajudavan no que fosse necessário. 0 tempo de preenchimento foi de 35 a 45 minutos ( $1^{\circ}$ ano) e de 30 a 40 minutos ( $2^{\circ}$ ano).

- Alunos de $3^{\circ}$ e $4^{\circ}$ anos. $O$ questionário foi entregue a cada aluno, que o preencheu em silêncio. Quando surgia uma dúvida, a criança levantava a mão e era ajudada pela professora titular de turma ou pelo investigador deste estudo. Estes alunos preencheram os questionários rapidamente (20 a 30 minutos) e raramente surgiram dúvidas.

A informação recolhida foi sujeita a tratamento e análise estatística descritiva através da frequência e da percentagem e a estatística inferencial através do teste do Qui-Quadrado para verificar a existência de diferenças estatisticamente significativas entre género e ano de escolaridade. Para este tratamento estatístico foi utilizado o software Statistical Package for the Social Sciences (SPSS), Windows (versão 19).

Das respostas das crianças emergiram as categorias apresentadas ao longo da investigação nas correspondentes tabelas.

\section{RESULTADOS}

\subsection{Jogos realizados e preferidos no recreio atendendo ao género}

Dos jogos realizados pelos alunos no recreio escolar, atendendo ao género e cujos resultados apresentamos na Tabela 1, salientamos o facto de o "pião" não poder ser utilizado pelos alunos no recreio escolar, simplesmente, por ser proibido na escola.

Alguns jogos, apesar de realizados por poucos alunos, apresentam diferenças significativas $(p \leq 0,001)$ quanto ao género, tal como "saltar ao elástico" que é um jogo realizado sobretudo pelas raparigas (12,0\%), sendo que só um rapaz o realiza $(0,6 \%)$; jogar aos "berlindes ou com caricas" é mais praticado pelos rapazes $(8,4 \%)$ do que pelas raparigas $(2,0 \%)$, também com diferenças significativas ( $p \leq 0,05)$; assim como o jogo das "damas" e os "puzzles", que encontram mais adeptos masculinos (8,4\% e 6,0\%) do que femininos $(2,0 \%$ e $1,3 \%)$, havendo também diferenças significativas em ambos os jogos quanto ao género $(p \leq 0,05)$.

Ainda em relação aos jogos apresentados no Quadro 1, salientamos aqueles que são mais realizados pelos alunos, atendendo às diferenças entre género. Assim, apresentamos inicialmente, por ordem decrescente, os seis jogos mais realizados pelas raparigas: "correr", "conversar", "caçadinhas", "saltar à corda", "escondidas" e "macaca"; quanto aos rapazes, os seis jogos mais realizados são: "correr", "futebol", "caçadinhas", "escondidas", "conversar" e "lutas". O jogo mais realizado tanto por rapazes como por raparigas é "correr", ainda que uma maior percentagem de rapazes $(82,6 \%)$ do que de raparigas $(78,7 \%)$ o realize. 
Tabela 1 - Jogos realizados no recreio: diferenças entre género

\begin{tabular}{|c|c|c|c|c|c|c|c|}
\hline \multirow{2}{*}{$\begin{array}{c}\text { Jogos } \\
\text { Realizados }\end{array}$} & & \multicolumn{2}{|c|}{ Rapaz } & \multicolumn{2}{|c|}{ Rapariga } & \multirow{2}{*}{$\begin{array}{c}\begin{array}{c}\text { Total } \\
(n=317)\end{array} \\
\text { Sim }\end{array}$} & \multirow[t]{2}{*}{$\mathrm{p}$} \\
\hline & & Não & Sim & Não & Sim & & \\
\hline \multirow{2}{*}{ Pião } & $\mathrm{n}$ & 167 & 0 & 150 & 0 & 0 & \multirow{2}{*}{ NS } \\
\hline & $\%$ & 100,0 & 0,0 & 100,0 & 0,0 & 0,0 & \\
\hline \multirow{2}{*}{ Saltar ao elástico } & $\mathrm{n}$ & 166 & 1 & 132 & 18 & 19 & \multirow{2}{*}{${ }^{* * *} 0,000$} \\
\hline & $\%$ & 99,4 & 0,6 & 88,0 & 12,0 & 6,0 & \\
\hline \multirow{2}{*}{ Macaca } & $n$ & 137 & 30 & 82 & 68 & 98 & \multirow{2}{*}{${ }^{* * *} 0,000$} \\
\hline & $\%$ & 82,0 & 18,0 & 54,7 & 45,3 & 30,9 & \\
\hline \multirow{2}{*}{ Saltar à corda } & $n$ & 139 & 28 & 57 & 93 & 121 & \multirow{2}{*}{${ }^{* * *} 0,000$} \\
\hline & $\%$ & 83,2 & 16,8 & 38,0 & 62,0 & 38,2 & \\
\hline \multirow{2}{*}{ Correr } & $\mathrm{n}$ & 29 & 138 & 32 & 118 & 256 & \multirow{2}{*}{ NS } \\
\hline & $\%$ & 17,4 & 82,6 & 21,3 & 78,7 & 80,8 & \\
\hline \multirow{2}{*}{ Escondidas } & $\mathrm{n}$ & 60 & 107 & 66 & 84 & 191 & \multirow{2}{*}{ NS } \\
\hline & $\%$ & 35,9 & 64,1 & 44,0 & 56,0 & 60,3 & \\
\hline \multirow{2}{*}{ Caçadinhas } & $\mathrm{n}$ & 55 & 112 & 54 & 96 & 208 & \multirow{2}{*}{ NS } \\
\hline & $\%$ & 32,9 & 67,1 & 36,0 & 64,0 & 65,6 & \\
\hline \multirow{2}{*}{ Futebol } & $\mathrm{n}$ & 42 & 125 & 125 & 25 & 150 & \multirow{2}{*}{${ }^{* \star *} 0,000$} \\
\hline & $\%$ & 25,1 & 74,9 & 83,3 & 16,7 & 47,3 & \\
\hline \multirow{2}{*}{ Dança } & $\mathrm{n}$ & 157 & 10 & 99 & 51 & 61 & \multirow{2}{*}{${ }^{* * *} 0,000$} \\
\hline & $\%$ & 94,0 & 6,0 & 66,0 & 34,0 & 19,2 & \\
\hline Ouvir múcica & $\mathrm{n}$ & 151 & 16 & 118 & 32 & 48 & 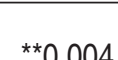 \\
\hline Gavir indusica & $\%$ & 90,4 & 9,6 & 78,7 & 21,3 & 15,1 & 0,004 \\
\hline Conversar & $n$ & 76 & 91 & 43 & 107 & 198 & **00005 \\
\hline Goriversal & $\%$ & 45,5 & 54,5 & 28,7 & 71,3 & 62,5 & 0,002 \\
\hline Desonher & $n$ & 147 & 20 & 103 & 47 & 67 & 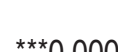 \\
\hline Desennar & $\%$ & 88,0 & 12,0 & 68,7 & 31,3 & 21,1 & 0,000 \\
\hline Ioto & $\mathrm{n}$ & 166 & 1 & 148 & 2 & 3 & NS \\
\hline & $\%$ & 99,4 & 0,6 & 98,7 & 1,3 & 0,9 & \\
\hline Berlindes, & $n$ & 153 & 14 & 147 & 3 & 17 & * 012 \\
\hline caricas & $\%$ & 91,6 & 8,4 & 98,0 & 2,0 & 5,4 & 0,016 \\
\hline Iutac & $\mathrm{n}$ & 97 & 70 & 143 & 7 & 77 & ${ }^{* \star *} \cap \cap 000$ \\
\hline Lutas & $\%$ & 58,1 & 41,9 & 95,3 & 4,7 & 24,3 & 0,000 \\
\hline Faz de conta & $\mathrm{n}$ & 146 & 21 & 88 & 62 & 83 & ${ }^{* \star *} 0.000$ \\
\hline & $\%$ & 87,4 & 12,6 & 58,7 & 41,3 & 26,2 & 0,000 \\
\hline Damas & $\mathrm{n}$ & 153 & 14 & 147 & 3 & 17 & *0.012 \\
\hline & $\%$ & 91,6 & 8,4 & 98,0 & 2,0 & 5,4 & \\
\hline Cartas & $n$ & 139 & 28 & 141 & 9 & 37 & $* * 0003$ \\
\hline 年 & $\%$ & 83,2 & 16,8 & 94,0 & 6,0 & 11,7 & 0,000 \\
\hline$P_{117709}$ & $n$ & 157 & 10 & 148 & 2 & 12 & * \\
\hline ruLCIES & $\%$ & 94,0 & 6,0 & 98,7 & 1,3 & 3,8 & 0,000 \\
\hline Inans eletrónicos & $n$ & 129 & 38 & 141 & 9 & 47 & ** \\
\hline sogos eletionilicos & $\%$ & 77,2 & 22,8 & 94,0 & 6,0 & 14,8 & 0,000 \\
\hline Outros ingos & $\mathrm{n}$ & 114 & 53 & 117 & 33 & 86 & $* * * \cap \cap 001$ \\
\hline Uutros jogos & $\%$ & 68,2 & 31,8 & 78,0 & 22,0 & 27,1 & 0,001 \\
\hline
\end{tabular}


Relativamente aos jogos que os alunos preferem realizar no recreio atendendo ao género, apresentamos os resultados na Tabela 2. Os alunos puderam selecionar dois jogos preferidos, sendo que em primeiro colocaram o que mais preferem realizar (atividade preferida 1) e de seguida o segundo jogo preferido (atividade preferida 2).

Tabela 2 - Jogos preferidos: diferenças entre género

\begin{tabular}{|c|c|c|c|c|c|c|c|c|c|c|c|}
\hline \multirow{3}{*}{ Jogos } & & \multicolumn{4}{|c|}{ Jogo preferido 1 (JP1) } & \multicolumn{4}{|c|}{ Jogo preferido 2 (JP2) } & \multirow{2}{*}{\multicolumn{2}{|c|}{$\begin{array}{c}\text { JP1+JP2 } \\
\text { Género } \\
\text { Total }\end{array}$}} \\
\hline & & \multicolumn{2}{|c|}{ Género } & \multirow{2}{*}{$\begin{array}{c}\text { Total } \\
(n=317)\end{array}$} & \multirow{2}{*}{$p$} & \multicolumn{2}{|c|}{ Género } & \multirow{2}{*}{$\begin{array}{c}\text { Total } \\
(n=317)\end{array}$} & \multirow{2}{*}{$p$} & & \\
\hline & & 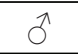 & $q$ & & & $\hat{0}$ & q & & & 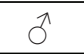 & q \\
\hline \multirow{2}{*}{ Futebol } & $\mathrm{n}$ & 73 & 8 & 81 & \multirow{2}{*}{${ }^{* * *} 0,000$} & 20 & 7 & 27 & \multirow{2}{*}{${ }^{* * *} 0,000$} & 93 & 15 \\
\hline & $\%$ & 43,7 & 5,3 & 25,6 & & 12,0 & 4,7 & 8,5 & & 55,7 & 10,0 \\
\hline \multirow{2}{*}{ Saltar à corda } & $\mathrm{n}$ & 0 & 44 & 44 & \multirow{2}{*}{${ }^{* * *} 0,000$} & 5 & 10 & 15 & \multirow{2}{*}{ NS } & 5 & 54 \\
\hline & $\%$ & 0,0 & 29,3 & 13,9 & & 3,0 & 6,7 & 4,7 & & 3,0 & 36,0 \\
\hline \multirow{2}{*}{ Caçadinhas } & $\mathrm{n}$ & 17 & 18 & 34 & \multirow{2}{*}{ NS } & 24 & 21 & 45 & \multirow{2}{*}{ NS } & 41 & 39 \\
\hline & $\%$ & 10,2 & 12,0 & 11,0 & & 14,4 & 14,0 & 14,2 & & 24,6 & 26,0 \\
\hline \multirow{2}{*}{ Correr } & $n$ & 16 & 13 & 29 & \multirow{2}{*}{ NS } & 16 & 15 & 31 & \multirow{2}{*}{ NS } & 32 & 28 \\
\hline & $\%$ & 9,6 & 8,7 & 9,1 & & 9,6 & 10,0 & 9,8 & & 19,2 & 18,7 \\
\hline \multirow{2}{*}{ Dança } & $n$ & 0 & 11 & 11 & \multirow{2}{*}{${ }^{* * *} 0,000$} & 0 & 7 & 7 & \multirow{2}{*}{${ }^{\star *} 0,005$} & 0 & 18 \\
\hline & $\%$ & 0,0 & 7,3 & 3,5 & & 0,0 & 4,7 & 2,2 & & 0,0 & 12,0 \\
\hline \multirow{2}{*}{ Escondidas } & $n$ & 7 & 5 & 12 & 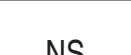 & 24 & 13 & 37 & IS & 31 & 18 \\
\hline & $\%$ & 4,2 & 3,3 & 3,8 & INS & 14,4 & 8,7 & 11,7 & NS & 28,6 & 12,0 \\
\hline to & $n$ & 6 & 6 & 12 & $\mathrm{NC}$ & 5 & 6 & 11 & IS & 11 & 12 \\
\hline conta & $\%$ & 3,6 & 4,0 & 3,8 & INS & 3,0 & 4,0 & 3,5 & No & 9,0 & 8,0 \\
\hline $\cos _{0} a^{-a}$ & $\mathrm{n}$ & 3 & 6 & 9 & $s$ & 1 & 17 & 18 & & 4 & 23 \\
\hline conversar & $\%$ & 1,8 & 4,0 & 2,8 & NS & 0,6 & 11,3 & 5,7 & 0 & 2,4 & 15,3 \\
\hline & $\mathrm{n}$ & 0 & 4 & 4 & & 0 & 2 & 2 & IS & 0 & 6 \\
\hline inar & $\%$ & 0,0 & 2,7 & 1,3 & & 0,0 & 1,3 & 0,6 & INS & 0,0 & 4,0 \\
\hline & $\mathrm{n}$ & 0 & 7 & 7 & & 1 & 6 & 7 & $\mathrm{NC}$ & 1 & 13 \\
\hline aca & $\%$ & 0,0 & 4,7 & 2,2 & & 0,6 & 4,0 & 2,2 & No & 0,6 & 8,7 \\
\hline Saltar ao & $\mathrm{n}$ & 0 & 4 & 4 & & 0 & 1 & 1 & NS & 0 & 5 \\
\hline elástico & $\%$ & 0,0 & 2,7 & 1,3 & & 0,0 & 0,7 & 0,3 & TVS & 0,0 & 3,4 \\
\hline & $n$ & 3 & 0 & 3 & IS & 6 & 0 & 6 & & 9 & 0 \\
\hline $\operatorname{sog} 00$ & $\%$ & 1,8 & 0,0 & 0,9 & NS & 3,6 & 0,0 & 1,9 & & 5,4 & 0,0 \\
\hline Jogos & $n$ & 0 & 0 & 0 & IS & 3 & 0 & 3 & $\mathrm{NC}$ & 3 & 0 \\
\hline eletrónicos & $\%$ & 0,0 & 0,0 & 0,0 & NS & 1,8 & 0,0 & 0,9 & INS & 1,8 & 0,0 \\
\hline$\Omega$ & $n$ & 1 & 1 & 2 & C & 1 & 1 & 2 & NC & 2 & 2 \\
\hline UUvir IIIUSICa & $\%$ & 0,6 & 0,7 & 0,6 & NS & 0,6 & 0,7 & 0,6 & IVS & 1,2 & 1,4 \\
\hline Jogo com & $n$ & 7 & 0 & 7 & & 8 & 1 & 9 & & 15 & 1 \\
\hline brinquedos & $\%$ & 4,2 & 0,0 & 2,2 & & 4,8 & 0,7 & 2,8 & & 9,0 & 0,7 \\
\hline Jogo de & $\mathrm{n}$ & 1 & 1 & 2 & JS & 8 & 1 & 9 & & 9 & 2 \\
\hline cartas & $\%$ & 0,6 & 0,7 & 0,6 & V & 4,8 & 0,7 & 2,8 & & 5,4 & 1,4 \\
\hline
\end{tabular}

Legenda: $\widehat{\partial}$-género masculino; + - género feminino; ${ }^{* *} p \leq 0,001 ;{ }^{* *} p \leq 0,01 ;{ }^{*} p \leq 0,05$; NS - não significativo Fonte: elaboração própria

Podemos então verificar que os jogos preferidos 1 pelos rapazes são: "futebol" (43,7\%), "caçadinhas" (10,2\%) e "correr" (9,6\%) e os jogos preferidos 1 pelas raparigas são: "saltar à corda" (29,3\%), "caçadinhas" (12,0\%) e "correr" (8,7\%). Os jogos, "caçadinhas" e "correr" 
aparecem, respetivamente, como segundo e terceiro jogos mais preferidos por ambos os sexos, não apresentando diferenças significativas quanto ao género. Enquanto o jogo "futebol" se apresenta como o preferido pelos rapazes (43,7\%), e apenas é preferido por $5,3 \%$ das raparigas, com diferenças significativas quanto ao género $(p \leq 0,001)$, também existem diferenças significativas $(p \leq 0,001)$ quanto ao género em relação ao primeiro jogo preferido pelas raparigas "saltar à corda", pois $29,3 \%$ das raparigas mencionam este jogo como preferido e nenhum rapaz menciona como preferido.

Em relação ao jogo preferido 2, constatamos que os rapazes mencionaram "caçadinhas $(14,4 \%)$ e escondidas (14,4\%), "futebol" $(12,0 \%)$ e "correr" $(9,6 \%)$, sendo que o "futebol" apresenta diferenças significativas ( $p \leq 0,001)$ em relação ao género, pois a atividade preferida 2 de apenas 4,7\% das raparigas. Quanto às raparigas, os jogos preferidos 2 são: "caçadinhas" $(14,0 \%)$, "conversar" (11,3\%) e "correr" (10,0\%), sendo que "conversar" apresenta diferenças significativas $(p \leq 0,001)$ quanto ao género, pois é preferido apenas por $0,6 \%$ dos rapazes.

Salientamos das Tabelas 1 e 2 que, quanto ao género, são as raparigas que mais diversificam e exploram diferentes jogos no recreio escolar. Serão os rapazes mais determinados e decididos no que toca à escolha dos seus jogos, ou são as raparigas mais criativas e imaginativas na hora de brincar e jogar com os seus pares?

Quanto aos jogos preferidos por rapazes e raparigas, atestamos que estes correspondem a alguns dos jogos que são mais praticados por ambos os sexos no recreio escolar. É curioso observar que as raparigas são bem mais seletivas quando se trata dos jogos preferidos do que quando se referem aos jogos realizados. "Correr" e "conversar" para ambos os sexos é o que mais fazem no recreio diariamente, no entanto, nenhum destes jogos/atividades foi referido como mais preferido por nenhum género.

\subsection{Jogos realizados e preferidos no recreio atendendo ao ano de escolaridade}

Relativamente à Tabela 3 apresentamos, por ordem decrescente, os jogos mais realizados pelos alunos, de acordo com 0 ano de escolaridade.

Tabela 3 - Jogos realizados no recreio: diferenças entre ano de escolaridade

\begin{tabular}{|c|c|c|c|c|c|c|}
\hline \multirow{3}{*}{$\begin{array}{c}\text { Jogos } \\
\text { Realizados }\end{array}$} & \multicolumn{4}{|c|}{ Ano de escolaridade } & \multirow{3}{*}{$\begin{array}{c}\begin{array}{c}\text { Total } \\
(\mathrm{n}=317)\end{array} \\
\text { Sim }\end{array}$} & \multirow{3}{*}{$p$} \\
\hline & \multicolumn{2}{|c|}{$1^{\circ}$ e $2^{\circ}$} & \multicolumn{2}{|c|}{$3^{\circ}$ e $4^{\circ}$} & & \\
\hline & Não & Sim & Não & Sim & & \\
\hline \multirow{2}{*}{ Pião } & 170 & 0 & 147 & 0 & 0 & \multirow{2}{*}{ NS } \\
\hline & 100,0 & 0,0 & 100,0 & 0,0 & 0,0 & \\
\hline \multirow{2}{*}{ Saltar ao elástico } & 157 & 13 & 141 & 6 & 19 & \multirow{2}{*}{ NS } \\
\hline & 92,4 & 7,6 & 95,9 & 4,1 & 6,0 & \\
\hline \multirow{2}{*}{ Macaca } & 103 & 67 & 116 & 31 & 98 & \multirow{2}{*}{${ }^{* * *} 0,001$} \\
\hline & 60,6 & 39,4 & 78,9 & 21,1 & 30,9 & \\
\hline \multirow{2}{*}{ Saltar à corda } & 104 & 66 & 92 & 55 & 121 & \multirow{2}{*}{ NS } \\
\hline & 61,2 & 38,8 & 62,6 & 37,4 & 38,2 & \\
\hline \multirow{2}{*}{ Correr } & 27 & 143 & 34 & 113 & 256 & \multirow{2}{*}{ NS } \\
\hline & 15,9 & 84,1 & 23,1 & 76,9 & 80,8 & \\
\hline
\end{tabular}


... continuação da tabela 3.

\begin{tabular}{|c|c|c|c|c|c|c|}
\hline \multirow{2}{*}{ Escondidas } & 78 & 92 & 48 & 99 & 191 & \multirow{2}{*}{${ }^{*} 0,021$} \\
\hline & 45,9 & 54,1 & 32,7 & 67,3 & 60,3 & \\
\hline \multirow{2}{*}{ Caçadinhas } & 74 & 96 & 35 & 112 & 208 & \multirow{2}{*}{$* * * 0,000$} \\
\hline & 43,5 & 56,5 & 23,8 & 76,2 & 65,6 & \\
\hline \multirow{2}{*}{ Futebol } & 94 & 76 & 73 & 74 & 150 & \multirow{2}{*}{ NS } \\
\hline & 55,3 & 44,7 & 49,7 & 50,3 & 47,3 & \\
\hline \multirow{2}{*}{ Dança } & 132 & 38 & 124 & 23 & 61 & \multirow{2}{*}{ NS } \\
\hline & 77,6 & 22,4 & 84,4 & 15,6 & 19,2 & \\
\hline \multirow{2}{*}{ Ouvir música } & 137 & 33 & 132 & 15 & 48 & \multirow{2}{*}{${ }^{*} 0,027$} \\
\hline & 80,6 & 19,4 & 89,8 & 10,2 & 15,1 & \\
\hline \multirow{2}{*}{ Conversar } & 56 & 114 & 63 & 84 & 198 & \multirow{2}{*}{ NS } \\
\hline & 32,9 & 67,1 & 42,9 & 57,1 & 62,5 & \\
\hline \multirow{2}{*}{ Desenhar } & 117 & 53 & 133 & 14 & 67 & \multirow{2}{*}{${ }^{* * *} 0,000$} \\
\hline & 68,8 & 31,2 & 90,5 & 9,5 & 21,1 & \\
\hline \multirow{2}{*}{ Loto } & 167 & 3 & 147 & 0 & 3 & \multirow{2}{*}{ NS } \\
\hline & 98,2 & 1,8 & 100,0 & 0,0 & 0,9 & \\
\hline \multirow{2}{*}{ Berlindes, caricas } & 154 & 16 & 146 & 1 & 17 & \multirow{2}{*}{${ }^{* * *} 0,000$} \\
\hline & 90,6 & 9,4 & 99,3 & 0,7 & 5,4 & \\
\hline \multirow{2}{*}{ Lutas } & 118 & 52 & 122 & 25 & 77 & \multirow{2}{*}{${ }^{* *} 0,006$} \\
\hline & 69,4 & 30,6 & 83,0 & 17,0 & 24,3 & \\
\hline \multirow{2}{*}{ Faz de conta } & 100 & 70 & 134 & 13 & 83 & \multirow{2}{*}{${ }^{* * *} 0,000$} \\
\hline & 58,8 & 41,2 & 91,2 & 8,8 & 26,2 & \\
\hline \multirow{2}{*}{ Damas } & 154 & 16 & 146 & 1 & 17 & \multirow{2}{*}{ *** 0,000} \\
\hline & 90,6 & 9,4 & 99,3 & 0,7 & 5,4 & \\
\hline \multirow{2}{*}{ Cartas } & 143 & 27 & 137 & 10 & 37 & \multirow{2}{*}{${ }^{*} 0,014$} \\
\hline & 84,1 & 15,9 & 93,2 & 6,8 & 11,7 & \\
\hline \multirow{2}{*}{ Puzzles } & 159 & 11 & 146 & 1 & 12 & \multirow{2}{*}{${ }^{* *} 0,007$} \\
\hline & 93,5 & 6,5 & 99,3 & 0,7 & 3,8 & \\
\hline \multirow{2}{*}{ Jogos eletrónicos } & 143 & 27 & 127 & 20 & 47 & \multirow{2}{*}{ NS } \\
\hline & 84,1 & 15,9 & 86,4 & 13,6 & 14,8 & \\
\hline Outroci & 111 & 59 & 120 & 27 & 86 & \\
\hline vutros jogos & 65,3 & 34,7 & 81,6 & 18,4 & 27,1 & 0,000 \\
\hline
\end{tabular}

Legenda: ${ }^{* *} p \leq 0,001 ;{ }^{* *} p \leq 0,01 ;{ }^{*} p \leq 0,05 ; N S-$ não significativo

Fonte: elaboração própria

Assim, os alunos dos $1^{\circ}$ e $2^{\circ}$ anos realizam mais frequentemente no recreio: "correr", "conversar", "caçadinhas", "escondidas", "futebol" e "faz de conta" e, por sua vez, os jogos mais realizados pelos alunos dos $3^{\circ}$ e 4ํanos são: "correr", "caçadinhas", "escondidas", "conversar", "futebol" e "saltar à corda". "Correr" é sem dúvida o que todos os alunos mais fazem no recreio, ainda que a percentagem dos alunos dos $1^{\circ}$ e $2^{\circ}$ anos $(84,1 \%)$ que a realiza seja superior à dos alunos dos $3^{\circ}$ e $4^{\circ}$ anos $(76,9 \%)$, não existem diferenças significativas.

O jogo "caçadinhas", que aparece como o segundo jogo mais realizado pelos alunos dos $3^{\circ}$ e $4^{\circ}$ anos $(76,2 \%)$ e o terceiro mais realizada pelos alunos dos $1^{\circ}$ e $2^{\circ}$ anos $(56,5 \%)$, apresenta diferenças significativas quanto ao ano de escolaridade $(p \leq 0,001)$. São os alunos dos $1^{\circ}$ e $2^{\circ}$ anos que mais referem "conversar" $(67,1 \%)$, sendo este 0 seu segundo jogo mais 
realizado, e para $57,1 \%$ dos alunos dos $3^{\circ}$ e $4^{\circ}$ anos este é o quarto mais realizado, não existindo diferenças significativas quanto ao ano de escolaridade.

Após a apresentação e análise das práticas lúdicas realizadas pelas crianças nos recreios escolares, vamos apresentar as práticas preferidas na Tabela 4.

Tabela 4 - Jogos preferidos: diferenças entre ano de escolaridade

\begin{tabular}{|c|c|c|c|c|c|c|c|c|c|}
\hline \multirow{3}{*}{ Jogos } & & \multicolumn{4}{|c|}{ Jogo preferido 1 (JP1) } & \multicolumn{4}{|c|}{ Jogo preferido 2 (JP2) } \\
\hline & & \multicolumn{2}{|c|}{$\begin{array}{c}\text { Ano de } \\
\text { escolaridade }\end{array}$} & \multirow[t]{2}{*}{$\begin{array}{c}\text { Total } \\
(n=317)\end{array}$} & \multirow[t]{2}{*}{$\mathrm{p}$} & \multicolumn{2}{|c|}{$\begin{array}{c}\text { Ano de } \\
\text { escolaridade } \\
\text { (Total) }\end{array}$} & \multirow[t]{2}{*}{$\begin{array}{c}\text { Total } \\
(n=317)\end{array}$} & \multirow[t]{2}{*}{$p$} \\
\hline & & $1^{\circ}$ e $2^{\circ}$ & $3^{\circ}$ e $4^{\circ}$ & & & $1^{\circ}$ e $2^{\circ}$ & $3^{\circ}$ e $4^{\circ}$ & & \\
\hline \multirow{2}{*}{ Futebol } & $\mathrm{n}$ & 27 & 54 & 81 & \multirow{2}{*}{${ }^{* * *} 0,000$} & 16 & 11 & 27 & \multirow{2}{*}{ NS } \\
\hline & $\%$ & 15,9 & 36,7 & 25,6 & & 9,4 & 7,5 & 8,5 & \\
\hline \multirow{2}{*}{ Saltar à corda } & $\mathrm{n}$ & 26 & 18 & 44 & \multirow{2}{*}{ NS } & 8 & 7 & 15 & \multirow{2}{*}{ NS } \\
\hline & $\%$ & 15,3 & 12,2 & 13,9 & & 4,7 & 4,8 & 4,7 & \\
\hline \multirow{2}{*}{ Caçadinhas } & $\mathrm{n}$ & 15 & 20 & 35 & \multirow{2}{*}{ NS } & 14 & 31 & 45 & \multirow{2}{*}{ ***0,001 } \\
\hline & $\%$ & 8,8 & 13,6 & 11,0 & & 8,2 & 21,1 & 14,2 & \\
\hline \multirow{2}{*}{ Correr } & $\mathrm{n}$ & 11 & 18 & 29 & \multirow{2}{*}{ NS } & 12 & 19 & 31 & \multirow{2}{*}{ NS } \\
\hline & $\%$ & 6,5 & 12,2 & 9,1 & & 7,1 & 12,9 & 9,8 & \\
\hline \multirow{2}{*}{ Dança } & $\mathrm{n}$ & 7 & 4 & 11 & \multirow{2}{*}{ NS } & 3 & 4 & 7 & \multirow{2}{*}{ NS } \\
\hline & $\%$ & 4,1 & 2,7 & 3,5 & & 1,8 & 2,7 & 2,2 & \\
\hline \multirow{2}{*}{ Escondidas } & $\mathrm{n}$ & 4 & 8 & 12 & \multirow{2}{*}{ NS } & 11 & 26 & 37 & \multirow{2}{*}{${ }^{* *} 0,003$} \\
\hline & $\%$ & 2,4 & 5,4 & 3,8 & & 6,5 & 17,7 & 11,7 & \\
\hline ta & $\mathrm{n}$ & 6 & 6 & 12 & $S$ & 7 & 4 & 11 & NS \\
\hline collta & $\%$ & 3,5 & 4,1 & 3,8 & INS & 4,1 & 2,7 & 3,5 & INS \\
\hline & $n$ & 0 & 9 & 9 & & 6 & 12 & 18 & \\
\hline conversar & $\%$ & 0,0 & 4,8 & 2,8 & & 3,5 & 8,2 & 5,7 & NSS \\
\hline Desenhar & $\mathrm{n}$ & 2 & 2 & 4 & NS & 2 & 0 & 2 & NS \\
\hline vesennar & $\%$ & 1,2 & 1,4 & 1,3 & INS & 1,2 & 0,0 & 0,6 & INS \\
\hline Масаса & $\mathrm{n}$ & 4 & 3 & 7 & NS & 5 & 2 & 7 & NS \\
\hline & $\%$ & 2,4 & 2,0 & 2,2 & & 2,9 & 1,4 & 2,2 & \\
\hline Saltar an elástico & $\mathrm{n}$ & 3 & 1 & 4 & NS & 0 & 1 & 1 & NS \\
\hline Sartal au erastivo & $\%$ & 1,8 & 0,7 & 1,3 & 10 & 0,0 & 0,7 & 0,3 & 10 \\
\hline loan & $n$ & 2 & 1 & 3 & NS & 4 & 2 & 6 & NS \\
\hline Jugo de luta & $\%$ & 1,2 & 0,7 & 0,9 & & 2,4 & 1,4 & 1,9 & INS \\
\hline ofronicos & $\mathrm{n}$ & 0 & 0 & 0 & $\mathrm{~S}$ & 0 & 3 & 3 & NS \\
\hline Jugos eletiomicus & $\%$ & 0,0 & 0,0 & 0,0 & INO & 0,0 & 2,0 & 0,9 & NO \\
\hline Ouvir música & $n$ & 1 & 1 & 2 & NS & 1 & 1 & 2 & NS \\
\hline unvir musica & $\%$ & 0,6 & 0,7 & 0,6 & INO & 0,6 & 0,7 & 0,6 & INS \\
\hline Jogo com & $\mathrm{n}$ & 7 & 0 & 7 & 016 & 6 & 3 & 9 & NS \\
\hline brinquedos & $\%$ & 4,1 & 0,0 & 2,2 & 010 & 3,5 & 2,0 & 2,8 & TNO \\
\hline logn de cartas & $\mathrm{n}$ & 2 & 0 & 2 & JS & 5 & 4 & 9 & NS \\
\hline Jugu ue Callas & $\%$ & 1,2 & 0,0 & 0,6 & vo & 2,9 & 2,7 & 2,8 & INS \\
\hline
\end{tabular}

Legenda: ${ }^{* * *} p \leq 0,001 ;{ }^{* *} p \leq 0,01 ;{ }^{*} p \leq 0,05 ;$ NS - não significativo Fonte: elaboração própria

Dos resultados obtidos e apresentados na Tabela 4 podemos verificar que dos jogos de recreio preferidos 1 pelos alunos atendendo ao ano de escolaridade, apenas registamos 
diferenças significativas nos seguintes: "futebol" $(p \leq 0,001)$, "conversar" $(p \leq 0,001)$ e "jogo com brinquedos" $(p \leq 0,05)$, sendo que "conversar" e "futebol", são jogos mais preferidos pelos alunos mais velhos do que pelos mais novos, pois $4,8 \%$ dos alunos do $3^{\circ}$ e $4^{\circ}$ anos preferem "conversar" e nenhum aluno do $1^{\circ}$ e $2^{\circ}$ anos mencionou este como preferido.

Já o "futebol" é o jogo mais preferido por ambos os anos de escolaridade, no entanto são os alunos mais velhos que mais o preferem, uma vez que $36,7 \%$ dos alunos do $3^{\circ}$ e $4^{\circ}$ ano e $15,9 \%$ dos alunos do $1^{\circ}$ e $2^{\circ}$ ano o mencionam como preferido. Os alunos mais novos registam diferenças em relação aos mais velhos, apenas no "jogo com brinquedos", pois este não é mencionado como preferido pelos alunos mais velhos e é referido por $4,1 \%$ dos alunos mais novos.

Quanto ao jogo preferido 2 podemos observar, pela Tabela 4, que existem diferenças significativas $(p \leq 0,01)$ para os jogos "caçadinhas", preferido por $21,1 \%$ dos alunos do $3^{\circ}$ e $4^{\circ}$ anos e por $8,2 \%$ dos alunos do $1^{\circ}$ e $2^{\circ}$ anos e "escondidas", preferido por $17,7 \%$ dos alunos mais velhos e por $6,5 \%$ dos alunos mais novos.

A atividade preferida pelos rapazes e pelos 3ํㅜ e 4ํao é sem dúvida o "futebol", pois esta atividade apresenta diferenças significativas $(p \leq 0,001)$ quanto ao género e quanto ao ano de escolaridade, apesar de ser também a atividade preferida dos alunos dos $1^{\circ}$ e $2^{\circ}$ anos. Já para as raparigas a atividade preferida é "saltar à corda" e com diferenças significativas quanto ao género $(p \leq 0,001)$.

\section{DISCUSSÃO}

As questões relacionadas com o género são abordadas nos diferentes domínios do saber, como tal, no que toca ao estudo de crianças em situações de jogo no recreio escolar, as diferenças entre género são evidenciadas, pois a predominância de grupos do mesmo género é imediatamente observada nesse contexto (RODRIGUES, 2001). Aliás, Maccoby e Jacklin (1987) afirmam que a segregação do género é já bastante evidente nas crianças entre os $3 \mathrm{e}$ 4 anos de idade.

De uma maneira geral podemos verificar neste estudo que tanto rapazes como raparigas se envolvem em jogos bastante ativos no recreio, solicitando, esencialmente, habilidades motoras, como correr e saltar. Sendo que as raparigas apresentam diferenças significativas em relação ao género em vários jogos que se apresentam como jogos maioritariamente femininos, como confirmam Pomar e Neto (2000) e, quanto aos rapazes, estes apresentam diferenças significativas quanto ao género nos jogos de "luta" ou "futebol", o que corrobora, em parte, as estereotipias de género apresentadas por Pomar e Neto (2000).

Este estudo concorda com o trabalho de Sequeira e Pereira (2004) quanto aos jogos realizados pelos rapazes, mas difere quanto às raparigas serem menos ativas, pois neste estudo as raparigas demonstram fazer também jogos fisicamente bastantes ativos no recreio, o que contraria em parte os estudos de Pfister (1993) e de Holmes (2012), que nos indicam que os rapazes realizam atividades físicas mais vigorosas, como os jogos desportivos, e as raparigas preferem atividades mais sedentárias ou menos vigorosas, como caminhar pelo recreio, socializar ou saltar à corda. Em contrapartida, num estudo de Stellino et al. (2010) sobre a prática de atividades físicas nos recreios em escolas do $1^{0}$ ciclo, foi verificada a tendência dos 
rapazes serem mais ativos fisicamente do que as raparigas, no entanto, essas diferenças não foram significativas, sugerindo que as diferenças entre rapazes e raparigas nesta faixa etária são difíceis de detetar.

Podemos ver que as raparigas variam mais os seus jogos no recreio escolar do que os rapazes, apresentando diferenças significativas na prática de mais jogos quando comparadas com os rapazes. Este facto foi também observado no estudo de Boyle, Marshall e Robeson (2003), efetuado com crianças de 9 e 10 anos de idade. A faixa etária, a adaptabilidade e as capacidades das crianças também podem ser outros fatores importantes no que toca à separação das crianças nos jogos de recreio (LOURO, 1997). Também, nos estudos de Patte (2009) como no de Jarrett et al. (2001), ambos realizados em escolas do $1^{\circ}$ ciclo do ensino básico, é confirmado que as crianças no recreio têm prazer ao socializar com outras crianças, sendo as crianças mais velhas que mais se socializam. É curioso perceber que, no nosso estudo, apesar de não existirem diferenças significativas, são as crianças mais novas que mais socializam. Ainda que não tendo sido objeto de estudo, poderemos questionar se o facto de as crianças mais velhas utilizarem o telemóvel poderá estar relacionado com estas novas formas de socialização.

Pellegrini (2005) verificou que ao longo de um período de recreio escolar as crianças modificam comportamentos, refletindo-se nestes as suas atividades preferidas, o seu nível de envolvimento e também a duração do tempo dedicado a cada atividade. A corrida é dos jogos mais referidos por todas as crianças. Estes dados estão de acordo, em parte, com o estudo de Wurdig (2010), onde este anuncia que a corrida é o que os rapazes mais realizam no recreio, no entanto, o jogo preferido dos rapazes são os jogos de perseguição, o que concorda com estudos de Pereira e Neto (1997) e de Beckemkamp, Tornquist e Burgos (2011).

Condessa (2012), no seu estudo sobre as recordações de infância dos avós açorianos relativamente aos jogos e brincadeiras, concluiu que tanto o género masculino como o feminino privilegiavam os jogos de motricidade global. Estes e outros jogos tradicionais têm caído em desuso ao longo do tempo, como nos confirmam vários estudos realizados a nível nacional (CONDESSA; FIALHO, 2010; PACHECO, 1995; SERRA; SERRA, 2007; VARREGOSO, 2000), assim como no presente estudo o podemos confirmar, pois foram poucas as crianças que mencionaram realizar esses jogos no recreio.

\section{CONSIDERAÇÕES FINAIS}

Podemos concluir que, neste estudo, tanto rapazes como raparigas se envolvem em jogos motores bastante ativos e, também, nos jogos típicos de género (ainda que em menor percentagem). Destacam-se, assim, os jogos mais realizados pelas raparigas, como a corrida e os jogos de perseguição, que contrastam com estudos realizados anteriormente, enquanto os rapazes registam um constante nos seus jogos realizados no recreio ao longo do tempo. Este estudo sugere que existe uma tendência para os jogos mais realizados pelas raparigas se aproximarem dos jogos mais realizados pelos rapazes.

Os jogos mais realizados não correspondem aos preferidos pelos alunos, facto que confirma a pouca diversificação nos jogos realizados pelos alunos, o que nos sugere que a introdução de materiais no espaço de recreio e as intervenções lúdico-pedagógicas podem traduzir-se num enriquecimento das atividades lúdicas desenvolvidas pelas crianças neste 
espaço, contribuindo para uma maior experiência motora, uma vez que a realização de jogos com diferentes exigências e desafios permite à criança explorar e desenvolver o seu potencial motor, expandindo a sua ação tanto no contexto de recreio como nas suas rotinas diárias.

\section{REFERÊNCIAS}

AMÂNCIO, Lígia. Masculino e feminino: a construção social da diferença. Porto: Afrontamento, 1994.

BAPTISTA, Iraê. Metodologia de pesquisa em ciências sociais. Maputo: Escolar Editora, 2016.

BECKEMKAMP, Daiana; TORNQUIST, Luciana; BURGOS, Miria Suzana. Brincadeiras praticadas no recreio escolar e nas horas de lazer. Revista Digital Lecturas, Educación Física y Deportes, n. 156,

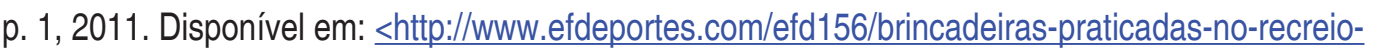
escolar.htm>. Acesso em: 2 ago. 2017.

BISQUERRA, Rafael. Metodología de la investigación educativa. Madrid: La Muralla, 2004.

BOYLE, Ellen; MARSHALL, Nancy; ROBESON, Wendy. Gender at Play. American Behavioral Scientist, v. 46, n. 10, p. 1326-1345, 2003.

CASAS, Juana; REPULLO, José Ramón; DONADO, Juan. La encuesta como técnica de investigación. Elaboración de cuestionarios y tratamiento estadísticos de los datos (I). Revista Atención Primaria, v. 31, n. 8, p. 527-538, 2003.

CEA, María Ángeles. Metodología cuantitativa: estrategias y técnicas de investigación social. Madrid: Síntesis, 2014.

CONDESSA, Isabel; FIALHO, Adolfo. (Re) aprender a brincar na barca do pirata. Ponta Delgada: Universidade dos Açores, 2010.

CONDESSA, Isabel. (Re) viver as brincadeiras e jogos de infância: o contributo para uma aprendizagem ao longo da vida. In: RAMOS, Natália; MARUJO, Manuela; BAPTISTA, Aida. A voz dos avós: migração, memória e património cultural. Coimbra: Gráfica de Coimbra e Pro Dignitate, 2012. p. 137-141.

DEMO, Pedro. Metodologia da investigação em educação. Curitiba: Ibpex, 2005.

GALLAHUE, David. Desenvolvimento Motor e Aquisição da Competência Motora na Educação de Infância. In: SPODEK, Bernard. Manual de Investigação em Educação de Infância. Lisboa: Fundação Calouste Gulbenkian, 2005. p. 49-83.

HARTEN, Nathan; OLDS, Timothy; DOLLMAN, James. The effects of gender, motor skills and play area on the free play activities of 8-11 years old school children. Health \& Place, v. 14, n. 3, p. 386$393,2008$.

HOLMES, Robyn. The outdoor recess activities of children at an urban school: longitudinal and intraperiod patterns. American Journal of Play, v. 4, n. 3, p. 327-351, 2012.

JARRETT, Olga et al. Boys and girls at play: Recess at a Southern urban elementary school. In: REIFEL, Robert Stuart. Theory in Context and Out: Play \& Culture Studies, n. 3, p. 147-170, 2001. 
KRITCHEVSKY, Sybil; PRESCOTT, Elizabeth. Planning environments for young children: Physical Space. Washington DC: National Association for the Education of Young Children, 1977.

LEVER, Janet. Sex differences in the complexity of children's play and games. American Sociological Review, v. 43, n. 4, p. 471-483, 1978.

LOURO, Guacira. Gênero, sexualidade e educação: uma perspectiva pós-estruturalista. Petrópolis: Vozes, 1997.

MACCOBY, Eleanor; JACKLIN, Carol. Gender segregation in childhood. Advances in child development and behaviour, v. 20, p. 239-287,1987.

MAGALHÃES, Manuela; HILL, Andrew. Investigação por questionário. Lisboa: Sílabo, 2016.

METZLER, Michael. Instructional Models for Physical Education. Arizona: Holcomb Hathaway, 2005.

MOURA, Diego Luz et al. Tempo livre e escola: uma análise das interações de escolares. Corpus et Scientia, v.8, n.1, p. 11-20, jun. 2012

MURRAY, Robert et al. The crucial role of recess in school. Pediatrics, v. 131, n. 1, p. 183-188, 2013.

NETO, Carlos. Motricidade e jogo na infância. Rio de Janeiro: Sprint, 2001.

PACHECO, Helder. A História dos Brinquedos in Rostos da Gente. Lisboa: Ministério da Educação, 1995.

PATTE, Michael. All in a day's work: children's views on play and work at the fifth grade level. In: KUSCHENER, David. From children to red hatters, Play \& culture studies, n. 8, p. 113-130, 2009.

PAWLOWSKI, Charlotte Skau et al. Barriers for recess physical activity: a gender specific qualitative focus group exploration. BMC Public Health, v.14, n.1, p. 639-649, jun. 2014.

PELLEGRINI, Anthony. Recess: it's role in education and development. Mahwah, NJ: Lawrence Erlbaum, 2005.

PEREIRA, Beatriz; NETO, Carlos. A infância e as práticas lúdicas: Estudo das atividades de tempos livres nas crianças dos 3 aos 10 anos. In: PINTO, Manuel; SARMENTO, Manuel Jacinto. As crianças: contextos e identidades. Braga: Centro de Estudos da Criança, Universidade do Minho, 1997. p. 219-264. (Colecção Infans).

PFISTER, Gertrud. Appropriation of the Environment, Motor Experiences and Sporting Activities of Girls and Women. International Review for the Sociology of Sport, v. 28, n. 2/3, p. 159-172, jun.1993.

PITCHER, Evelyn; SCHULTZ, Lynn. Boys and Girls at play: the development of sex roles. New York: Bergin \& Garvey, 1983.

POMAR, Clarinda; NETO, Carlos. Percepção da apropriação e do desempenho motor de género em actividades lúdico-motoras. In: NETO, Carlos. Jogo e Desenvolvimento da Criança. Lisboa: Edições FMH, 2000. p. 178-205.

RIDGERS, Nicola et al. Examining children's physical activity and play behaviors during school playtime over time. Health Education Research, v.26, n.4, p. 586-595, mar. 2011. 
RODRIGUES, Paula. Recreio: espaço de segregação. In: SANTOS DOS SANTOS, Edmilson. Olho mágico: o cotidiano, o debate e a crítica em Educação Física Escolar. Canoas: Ed. ULBRA, 2001. p. $211-220$.

ROHRMANN, Tim; EMILSEN, Kari. Editorial. European Early Childhood Education Research Journal, v.23, n.3, p. 295-301, aug. 2015.

SEQUEIRA, Anabela; PEREIRA, Beatriz. Estudo descritivo das actividades de tempos livres no ATL: um estudo de caso. In: CONGRESSO LUSO-AFRO-BRASILEIRO DE CIÊNCIAS SOCIAIS "A QUESTÃO SOCIAL NO NOVO MILÉNIO". 8. 2004. Coimbra: Universidade de Coimbra, 2004. Disponível em: <https://www.ces.uc.pt/lab2004/pdfs/AnabelaSequeira.pdf >. Acesso em: 2 ago. 2017.

SERRA, Cameira; SERRA, Nuno. Actividades lúdico-motoras praticadas em meio rural por crianças do $1^{\circ}$ ciclo do EB. Mudanças verificadas entre 1992 e 2007. ESEG Investigação, Revista científica da Escola Superior de Educação da Guarda, v.1, n. 4, p. 149-168, 2007.

STELLINO, Megan Babkes et al. Differences in Children's Recess Physical Activity: Recess Activity of the Week Intervention. Journal of School Health, v. 80, n. 9, p. 436-444, 2010.

SUTTON-SMITH, Brian. A History of children's play: New Zealand. Philadelphia: University of Pennsylvania , 1981.

TUCKMAN, Bruce. Manual de investigação em educação. Lisboa: Fundação Calouste Gulbenkian, 2012.

VARREGOSO, Isabel. Práticas lúdicas tradicionais infantis portuguesas: seu desaparecimento dos espaços de recreio escolar. Revista Educação e Comunicação, n. 3, p. 58-69, jun. 2000.

WALSH, Prue. Planning for play in a playground. Exchange, v. 30, n. 5, p. 88-94, 2008.

WURDIG, Rogério. Recreio: os sentidos do brincar do ponto de vista das crianças. InterMeio: Revista do Programa de Pós-Graduação em educação, v. 16, n. 32, p. 90-105, 2010. 
